\title{
Industrial Development in Rural Areas and the Flow of Home-coming Career-creating Talents under the Pattern of Double Circulation Economy
}

\author{
Jing Li \\ Guangdong Zhijingcheng Enterprise Management Consulting Co., Ltd.
}

\begin{abstract}
The global economic situation continues to change dramatically as the pandemic continues to affect the world. During the construction period of the 14th Five-year Plan, the new development pattern of strengthening the major domestic cycle as the main body and the double domestic and international cycles promoting each other has become an important strategic choice for China. However, decades of reform and opening up and urbanization have resulted in a shortage of talents for construction in rural industry in China, and there is a certain gap between the quantity and quality of rural revitalization and its internal needs. To revitalize ecological rural talents, promote the development of rural industry and upgrading is the key to the agglomeration of a lot of intellectual talents. Besides, we should take "nostalgia and locality" as the core of emotions based on the development mode of the upgrading of rural industrial chain to actively develop talents for rural revitalization in new era, which is of great importance for promoting rural revitalization.
\end{abstract}

Keywords: Double circular economy, Rural revitalization, Talent ecology, Returning to the countryside, Talent flow.

\section{Introduction}

The unbalanced response to COVID-19 has led to huge differences in economic recovery and development among countries, and the continuing impact of the epidemic has further aggravated the headwinds of globalization in the world economy. The trade game between major countries and economic and trade frictions have intensified, the international external circulation has been restricted, and uncertainties in global economic cooperation have increased. Various factors make it necessary for China to accelerate the formation of a new development pattern with the major domestic cycle as the main body and the double domestic and international cycles mutually reinforcing. This is also a major strategic choice for the construction of China's "14th Five-year Plan".

\section{Industrial Development in Rural Areas under the Rural Revitalization Strategy}

During the 14th Five-year Plan period, to further implement the rural revitalization strategy and promote the construction and upgrading of rural industries in a scientific and orderly way is an important way to realize the great cycle in China. The prosperity of the countryside is the prosperity of the country. The contradiction between unbalanced and inadequate development and the Chinese people's ever-growing needs for a better life is most prominent in the countryside, and it is in the countryside that we face the most arduous and arduous task of completing the building of a moderately prosperous society in all respects and building a great modern socialist country in all respects, but we should also see that the greatest potential for future development is also in the vast rural areas.

In Taishan, Jiangmen city, Guangdong Province, there is a village called Caopingli, which has been well developed for more than 600 years. In recent decades, due to the development and livelihood of the villagers, it has almost become an abandoned village. Since 2018, the descendants of the village have responded to the call of the government and returned to their hometown with nostalgia and love for their hometown, and carried out planning and renovation of the village with excellent construction team and brand project resources. Three years later, they succeeded in transforming this ancient impoverished village, which is mainly based on manual agriculture, into a comprehensive tourism network spot as idyllic scenery, nostalgic town of the Republic of China (1912-1949), and as the venue to hold music festival for youngsters and traditional handicraft exhibition, which can carry up to 20000 tourists a day. Relying on the unique style of southern ancient villages and the cultural deposits of overseas Chinese hometown, the next development of Caoli will be integrated into modern tourism planning, forming green agricultural ecological experience area, traditional culture and custom experience area, characteristic leisure and vacation experience area, and finally forming a characteristic town of Caoli brand.

In the process of the reconstruction of this village, village builders closely integrate characteristic towns, give new life to traditional villages with modern urban construction planning, and build a new pattern of integrated urban-rural development with ecological links. In the reconstruction, we try our best to restore the history, excavate the cultural symbols of rural characteristics, and strive to maintain the integrity and continuity of the village. The architectural layout of the village itself, rural scenery and other spatial resources can be adopted as far as possible to protect the ancestral monuments, traditional dwellings, etc. People who return to the village are also willing to respect and retain the living customs handed down from generation to generation, and rebuild the village infrastructure and public living space on the premise of rational use of village resources. On the one hand, the protection of resources can be completed, and on the other hand, the village can keep up with the pace of modern development.

China, with a long history, enjoys numerous regions with characteristics and rich cultural resources. Today, there are 
still a large number of traditional villages, historic residences, ethnic minority based villages and famous villages with tourism characteristics. These important carriers of traditional cultural inheritance are unique rural resources and the unique characteristics rendered by the time and folk culture of each place are the core competitiveness, which can meet the needs of more constantly upgrading and diversified consumption experience, thus forming a huge rural revitalization industry with different resource endowment.

However, China's urbanization process for many years has made rural talents to flood into cities and towns, as result, there is a lack of talents in rural construction. According to 2020 data released by China's 7th national census, China's rural population is 510 million, and urban population is 902 million. A large number of rural population has moved into cities, who mainly clustered in the Beijing-Tianjin-Hebei region, Yangtze River Delta and Pearl River Delta in the east, and Chengdu and Chongqing in the west. There is certain gap with the internal needs for rural revitalization in both scale and comprehensive quality of tyoes of talents in all areas.

\section{Rural Revitalization Relies on the Intellectual Support of Rural Talents}

\subsection{Labor Shortage}

3.1.1 Continuing loss of so called advantaged rural labor groups

After the reform and opening up, due to the attraction of income and improved living environment, the dominant rural labor force group began to "clustered" to cities due to the explosive growth of the second and third industries in cities, resulting in relatively slow rural development. The survey by the Agricultural Transfer Team of the National Bureau of Statistics shows that the number of rural migrant workers is increasing year by year. According to the 2016 Migrant Workers Monitoring Survey Report, the "new generation of migrant workers", namely the "post-80s" and "post-90s" migrant workers born between 1980 and 1994, have gradually become the main body of migrant workers, accounting for $49.7 \%$ of the total number of migrant workers in China. Among migrant workers, $26.4 \%$ have high school education or above. Among them, $29.1 \%$ went out, and only $23.9 \%$ were local migrant workers. Advantaged migrant workers with higher education degree are also relatively easy to outflow.

3.1.2 Talents who go out of the countryside can hardly return to the countryside

The popularization of compulsory education and the improvement of living standards have brought more talents to go out of rural areas. However, the relatively backward industrial resources in rural areas make it difficult for these people to return to rural areas to develop. Instead, they pour all their resources to strive to stay in cities and towns, which leads to the backward talent ecology in rural areas.

The rise and development of e-commerce and livestreaming industry make it possible for rural industries for sudden rise. However, restricted by the opportunity cost of employment and entrepreneurship as well as the difference in life style between urban and rural areas, the group that could have returned to rural development has become a group of "Beijing drifters", "Guangzhou drifters" in the city.

\subsubsection{Prosperity of rural industry attracts talents for rural} construction

The past 40 years of rural reform have proved that only by revitalizing rural industries can we make rural areas more attractive, and more capitals can be attracted, and technology, talents and other factors of production can be used in rural areas to give rural people the hope of "strong agriculture", "beautiful countryside" and "rich farmers". In the final analysis, only when rural industries flourish can rural vitalization be made possible. Only with a sufficient number of talents for rural construction, rural revitalization can be comprehensively developed in a sustained manner, so the key to solve the rural revitalization is to solve the lack of intellectual support of talents for rural construction.

\subsection{Suggestions on the Strategic Layout of Construction of Rural Talents}

3.2.1 "Nostalgia for hometown" is regarded as a new overall view for attracting rural talents

Since the reform and opening up, a considerable number of outstanding "strivers" - the dominant labor force groups who left their hometowns to seek opportunities in the early stage of the reform, coastal cities and provincial capital cities have left their hometowns to seek development elsewhere. Thirty years past, when these strivers achieved the stability of life, whether there will be "good east west good as good as home" simple hometown feelings? When they become outstanding entrepreneurs, highly skilled people, veterans, retirees, etc., are they willing to participate in the revitalization of their hometown?" Homesickness, homesickness, homesickness" as the emotional core, emotional links as an important way to attract talents back. Gather "strivers", let the rural talents who once "went out" "come back", and bring back the necessary development experience, advanced technology and capital to the hometown, so that the revitalization of the hometown can be realized.

\subsubsection{Relying on rural civilization to build up the feelings of} hometown

Since ancient times, "nostalgia for hometown" has been the lonely experience of countless wanderers, a call for a strong inner identity. For those outstanding talents from various industries who were born in rural areas and have established themselves in other places, through understanding their watch for homesickness, they can effectively transmit the culture and local customs of their hometown, awaken their identification and belonging feelings for "roots", and reshape their sense of honor and spiritual needs for self-value realization to urge them to return to their hometown. Organize and improve the "hometown talent resource bank", attract talents to return to their hometown to start their own business, open up the two-way service channel between talents and their hometown, make some overseas talents have a platform to serve their hometown, improve the degree of talent concentration, and continuously accumulate and expand the 
scope and resources of rural talents, so as to realize the desire of building their hometown.

\subsubsection{Talents construction project with "A Returning Letter"}

When talents return to rural areas and build rural areas, it is necessary to call on talents to return home for construction and actively build a "village sound bridge"—go out to "visit" and invite people to "talk". Actively introduce to outer local talent development and change of home and talent introduction policy, fully rely on e-commerce platform, trill platform, live platform, the public media such as mass media play the "nostalgia" brand, build love to worship to the social environment, promote talents, the development process of the timely transmission hometown in order to enhance for home pay attention to and understand, Targeted publicity of the development of hometown construction expectations, so as to realize the "striver" talents outside the hometown under the trend of hometown emotion, with projects, funds, talents and information to return to their hometown, contributing to the revitalization of rural development.

3.2.4 Cultivating and strengthening the returnee innovation and entrepreneurship groups

Rural revitalization needs to be diversified. Driven by returning talents, more rural personnel should be encouraged to start businesses locally and return to their hometowns, and rural industrial technological innovation alliances led by star individuals and star enterprises should be gradually formed, so that funds, technologies and projects can be spread with the advantages of "industries" and "industries". Combined with the current supportive policies of governments at all levels, technology pool resources of scientific research institutions, flexible market operation ability of enterprises and multi-social resources, rural pillar industries can realize innovation and entrepreneurship cluster on the traditional basis, and rural emerging industries can realize more practices and adjustments. Innovation and entrepreneurship drive rural revitalization by integrating traditional pillars with emerging industries and accelerating the flow of resources for urban and rural development.

3.2.5 Flexible and diverse channels to attract talents and wisdom

Rural revitalization and industrial development require various types of personnel, including professional and technical personnel, scientific and technological R\&D personnel and highly skilled personnel in industries and sectors. To retain these talents, first of all, we can learn from the flexible introduction principle of "not owning, but using" and encourage outstanding entrepreneurs, experts in science and technology, scientific research experts and multi-skilled talents to go to rural areas for field trips, industrial cooperation or investment and business development. Mutual understanding and cooperation can be carried out first to pave the way for further talent introduction. Second, relevant support strategies can be introduced in terms of land for entrepreneurship, tax incentives and fee reductions, and support can be provided in terms of information services, resource docking and logistics support. Thirdly, it is suggested to strengthen the continuous investment in rural infrastructure construction, improve the supply level and quality of education, medical care, culture and other public services, give full consideration to the actual working and living conditions of rural talents, provide livable living environment for all kinds of talents in rural areas, and enhance their sense of happiness and security.

\section{References}

[1] Wei Shanyuan, Yang Rende, Xiang Hua. Brain drain and new rural construction: Reflections on rural brain drain in China[J]. Guizhou Agricultural Sciences, 2009, 37 (9): 250-252.

[2] Reunderstanding of rural cultural value under rural revitalization Strategy $[\mathrm{J}]$. Guizhou Social Sciences, 2018, (1): 4-10.

[3] Huntington Samuel P. Who are we? The challenges to America's national identity[M]. New York: Simon \& Schuster, 2005.

[4] Opinions of the CPC Central Committee and the State Council on Implementing the Rural Revitalization Strategy. Available from: http://www.gov.cn/zhengce/2018-02/04/content_52638 07.htm

[5] Strategic Plan for Rural Revitalization (2018-2022). Available

from: http://www.moa.gov.cn/ztzl/xczx/xczxzlgh/201811/t20 181129_6163953.htm

[6] Proposal of the CPC Central Committee on Formulating the 14th Five-year Plan for National Economic and Social Development and the Long-term Goals for 2035. Available

from: http://www.gov.cn/zhengce/2020-11/03/content_55569 91.htm

[7] National Bureau of Statistics, Office of the Leading Group for the Seventh National Census of the State Council. Bulletin of the Seventh National Population Census. Available from: http://www.stats.gov.cn/tjsj/tjgb/rkpcgb/qgrkpcgb/2021 06/t20210628_1818820.html 